\title{
DEVELOPING NEW TECHNOLOGY PLATFORMS FOR NEW BUSINESS MODELS: SYNGENTA'S PARTNERSHIP WITH THE UNIVERSITY OF MANCHESTER
}

\author{
The university innovation center offers a model for industry-university collaboration \\ that explores both new technologies and the business models to support \\ their commercialization.
}

Khaleel Malik, Luke Georghiou, and Bruce Grieve

OVERVIEW: Evidence from academic studies and national-level policy reports suggests that universityindustry relationships are now widely practiced in many countries and increasing in importance. University innovation centers (UICs) offer one mechanism for managing these relationships. UICs are an instrument to mobilize a critical mass of researchers to build new technology platforms and enable the corporate partner to explore new business opportunities, a process that requires work on new business models to be carried out in parallel with technological research. As an example, the paper analyzes the partnership between agribusiness Syngenta AG and the University of Manchester (UK) to establish a UIC focused on the introduction of sensors and informatics into agriculture ("agri-electronics").
KEY CONCEPTS: Strategic partnership, Agriscience, Open innovation, Business-university partnership

Open innovation is now generally accepted as providing companies with a broad, long-term strategy for developing new technologies and exploring new markets. Frequently, an open-innovation program includes efforts to reach out to external researchers, in some cases by partnering with research-intensive universities. These partnerships may be aimed at solving specific problems or at providing windows on emerging technologies. While they can offer fruitful ground for identifying and developing innovations, these relationships do require careful management to ensure both parties' goals for the partnership are met.
Khaleel Malik is a senior lecturer at the Manchester Institute of Innovation Research at Manchester Business School (The University of Manchester). His career started in the engineering industry, where he worked in design and development and industrial marketing. After completing his PhD in technology management at the University of Manchester in 2000, he continued to work at Manchester as a researcher and lecturer. His research interests focus on the strategic management of technology within firms, technology transfer, knowledge management, and innovation policy-related studies. Khaleel is also book review editor of the journal R\&D Management. khaleel.malik@mbs.ac.uk

Luke Georghiou is professor of science and technology policy and management at the Manchester Institute of Innovation Research at Manchester Business School (The
University of Manchester). He was on the staff of its precursor institute, PREST, since 1977 and was its executive director from 1990-2004. luke.georghiou@mbs.ac.uk

Dr. Bruce Grieve is the director of the Syngenta university innovation center at the University of Manchester (UK). Bruce is a chartered engineer and Fellow of the Institute of Engineering and Technology. He has spent 20 years in the field of online analysis, measurement, and informatics $R \& D$ within pharmaceutical and biotechnology companies. Prior to taking on his current role in 2007, Bruce was based in Syngenta's new business development unit (Basel, Switzerland). Bruce has been awarded a Royal Academy of Engineering Senior Fellowship to support his sensors research and has been identified by the Science Media Centre as the spokesperson for e-Agri. bruce.grieve@manchester.ac.uk 
Syngenta AG, a global agribusiness company that markets seeds and pesticides, has developed a useful and effective mechanism for managing its university partnerships. Syngenta-sponsored university innovation centers (UICs) work to develop new technology platforms that can help move the company into new business opportunities. Since 2007, Syngenta has established six UICs across six universities or research institutes and three countries, each focused on a different set of technology opportunites. The UICs offer Syngenta another route for acquiring external technological capabilities, in addition to other, more traditional acquisition mechanisms, such as licensing technologies and collaborating with other kinds of external partners. At the same time, the UICs enable Syngenta to exploit these capabilities more readily by exploring different routes to market early in the development process. Where acquired technologies must usually then be fitted into a business model, Syngenta-sponsored UICs work with the company's business development teams to identify and validate a business model for the proposed technology before significant resources are invested in technical innovation. The technical work can then be shaped in development to match the requirements of the validated business model. The benefit of this approach is that the company can move its technical innovations in the most innovative and lucrative directions and minimize risk associated with developing business models to fit technology.

Syngenta's first UIC, established in partnership with the University of Manchester (UK) in 2007 to study the possible use of sensors in agribusiness applications, offers an example of a successful strategic partnership between business and academia. Known as the Syngenta Sensors Centre (SSC), the UIC has helped Syngenta explore new technologies, manage risk, and generate innovation.

\section{Accessing University Knowledge}

Various indicators suggest that knowledge transfer between universities and commercial firms is accelerating. This includes a rising numbers of patents filed by universities, increasing numbers of university researchers engaging in academic entrepreneurship, growing numbers of university spin-off companies, the growing share of industry funding in university income, and the diffusion of technology transfer offices and other knowledge transfer activities initiated through national or regional innovation support measures (Nelson 2001; Shane 2005). There is also abundant evidence to suggest that the process of knowledge transfer between universities and industry occurs through multiple channels, including informal contacts, personnel mobility, consulting relationships, and joint research projects (Arundel and Geuna 2004).

At the same time, recent changes in corporate $R \& D$ models - from centralized R\&D functions to R\&D divisions tied to particular products or businesses - have led to a shift in the nature of university-business relationships (Coombs and Georghiou 2002). Moving away from large portfolios of relationships with individual academics, many firms now establish long-term relationships with entire university departments; these arrangements typically cover equipment provision, staff posts, and graduate student recruitment. For example, Rolls-Royce Aero Engines has consolidated about 300 small, dispersed university projects into 28 large "university technology centers" (UTCs). Intel, Unilever, Hitachi, and Microsoft all have agreements with the University of Cambridge (UK) that allow them to integrate corporate $\mathrm{R} \& \mathrm{D}$ resources with university resources (Broström, McKelvey, and Sandström 2009), offering the companies access to academic researchers and providing the university with resources and an outlet for commercializing researchers' work.

In some cases, these kinds of collaborations may be situated in the context of a wider pattern of universityindustry collaborations. The University of Manchester, for instance, has pursued a wider strategy of building alliances with key corporate partners - including AstraZeneca, IBM, and BP as well as Syngenta - via a number of individual efforts. These broadband collaborations are designed to enable companies to commission and collaborate on research projects of mutual interest, work in partnership in developing and exploiting intellectual property (IP), develop staff skills and expertise through professional development activities and staff exchanges, build mutual trust through a relationship that is not dependent upon specific individuals, and tackle social and political issues affecting the business. A key benefit of such large-scale efforts is that transaction costs may be reduced by a framework agreement covering both research and training needs, which negates the need for separate contracts to cover research, training, and other knowledge-transfer activities. Furthermore, collaborations with multiple companies may make it easier for the university to access other sources of funds.

Conversely, no single university is likely to have the complete set of skills a company may require. Crossinstitutional research may be needed to satisfy a diverse or complex set of needs within a single area. As a result, some companies create a network of university-based research centers; Syngenta, for instance, maintains six UICs in the United Kingdom, China, and Australia, each with its own thematic focus.

Such relationships bring both benefits and challenges. Benefits can be both concrete, in the form of a flow of marketable innovations, and "soft," in, for example, the development of informal linkages between academic researchers and company $R \& D$ workers and a flow of qualified researchers to business. Roessner et al. (1998) 
found that the single most important benefit to industry from participation in the NSF Engineering Research Centers (ERCs), according to the industrial participants themselves, is the ability to hire ERC students and graduates. At the same time, these relationships can become problematic and controversial. The 1998-2003 partnership between the University of California-Berkeley and Novartis attracted substantial negative attention. The relationship was seen as controversial because it granted Novartis first license-negotiation rights for one-third of all departmental discoveries (including those funded by public entities like NIH), and it allowed Novartis scientists to earn adjunct status at the university for their work on Novartis projects. This was also among the first agreements to be made with an entire university department rather than with a single faculty member. Although no misconduct was uncovered in this case, Rudy et al. (2007) called for a multilevel and ongoing dialogue on the future of such large-scale agreements between public universities and large corporations. One lesson for companies entering such partnerships is to recognize that the collaboration can be difficult to manage because universities and business have different objectives, but the interactions do provide fresh insights that might not otherwise have happened.

Syngenta's UIC model enables companies to integrate corporate $R \& D$ resources with university resources as part of long-term strategic partnerships. In particular, UICs allow university academics to benefit from insights into the future business strategies of the partner company, while the sponsoring company gains access to the wider expertise available in the university community. The UIC structure may help overcome some of the problems that can arise in university-industry partnerships, as UIC outputs are evaluated at regular intervals over the lifespan of the UIC (which is typically three to five years). This process enables both partner organizations to review and assess the effectiveness of the collaboration and make adjustments in the relationship over time.

\section{The University Innovation Center}

The UIC concept is built upon the UTC model developed by Rolls-Royce since the mid-1980s. Like the UTC, the UIC comprises a nucleus of academic research staff and graduate students focused on specific areas deemed critical to the long-term strategy of the funding company. The management and coordination of the center is undertaken by the UIC director, a senior-level academic, in close contact with the sponsor firm. The UIC also has essentially the same IP protection and research publication agreements in place as the UTC.

The UIC differs from the UTC in one fundamental attribute. The UIC is conceptualized as an element of Syngenta's open-innovation strategy (Figure 1; Chesbrough 2003); it is intended not to supplement existing corporate

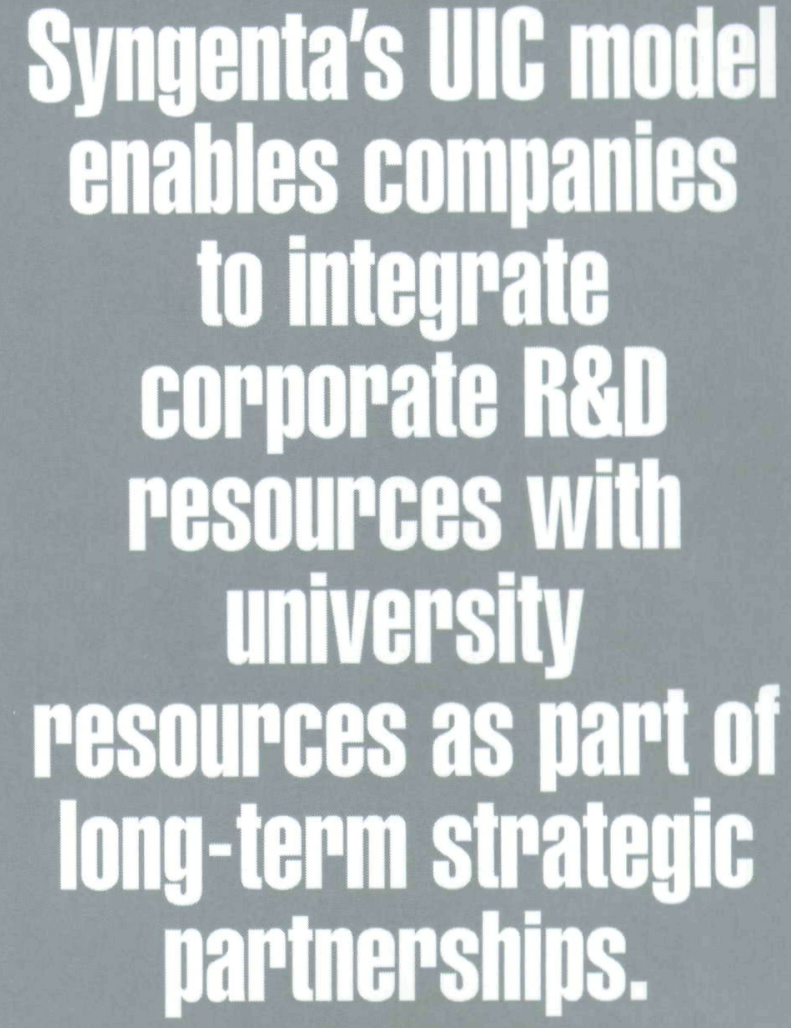

capabilities but to extend the company's technological capabilities. Where the UTC concept addresses technologies that are already core to the parent business, the UIC is focused on technologies that are not currently core to the host company and may never be. Instead, the UIC focuses on "technology themes" that will enable the sponsor company to integrate new technologies into its current product portfolio or move into new markets. In other words, the UIC develops both new technologies and the business models required to commercialize them. This is potentially the most innovative and lucrative direction for a company, but also the most risky.

The UIC model offers a number of advantages to each party. The sponsoring company gains access to skills and assets that do not reside in the company through a structure that creates a critical mass of research capability by configuring crossdisciplinary teams to address a related complex of technical questions (European Commission 2008). The university acquires a new line of funding, but there are other benefits as well. Academic participants may benefit from insights into the current and future strategies of an international company; with this insight, researchers can adapt their research focus to address anticipated needs, increasing the potential for future support of their work and for commercialization of the results.

At the same time, both parties must be well aware of the potential pitfalls. A previous U.K. comprehensive survey identified divergence of objectives between the university 
and industry participants as the most frequent problem area in university-industry collaborations (Howells, Nedeva, and Georghiou 1998). This divergence could be caused by changes in priorities on the industrial sidesometimes driven by changes in management or ownership - or on the academic side, driven by cultural factors that may steer the research in a different direction. In fact, differences in corporate and academic culture can become a separate source of tension that can block communication. The academic reward system can militate against cooperation, and business participants express persistent concerns about what is perceived as a lack of professionalism on the university side.

To avoid these problems, the sponsor company must manage the relationship carefully over time. In a recent study analyzing the outsourcing practices of Siemens (Germany's largest manufacturer and R\&D organization), Cui et al. (2009) stress the need for closer control of progress and knowledge transfer, especially in cases where the university may work in directions and toward ends that do not accord with company objectives. Avoiding such conflicts requires well-defined progress milestones to ensure that both company and academic participants are on track and in sync with the end goal. By allowing for a periodic check on progress and orientation, a system of milestones should help to defuse tensions and keep all participants motivated for the longer term.

Collaborating well with corporate partners should be seen as an organizational skill for the university, especially with long-term strategic partnerships like the UIC, as this encompasses not only doing collaboration well, but
The UIC foelises on

"technology themes" that will enalile the

sponsor company to integrate new teehnologies into its Eurrenti prodict portiolio or move into new markitets.

also feeding back knowledge from the experience into the institution. Similarly, in order to exploit this knowledge mix effectively in the market, companies must develop the internal capability to evaluate the strategic significance of knowledge being captured from a UIC partnership vis-à-vis knowledge captured from other types of external collaborations (Malik 2004).

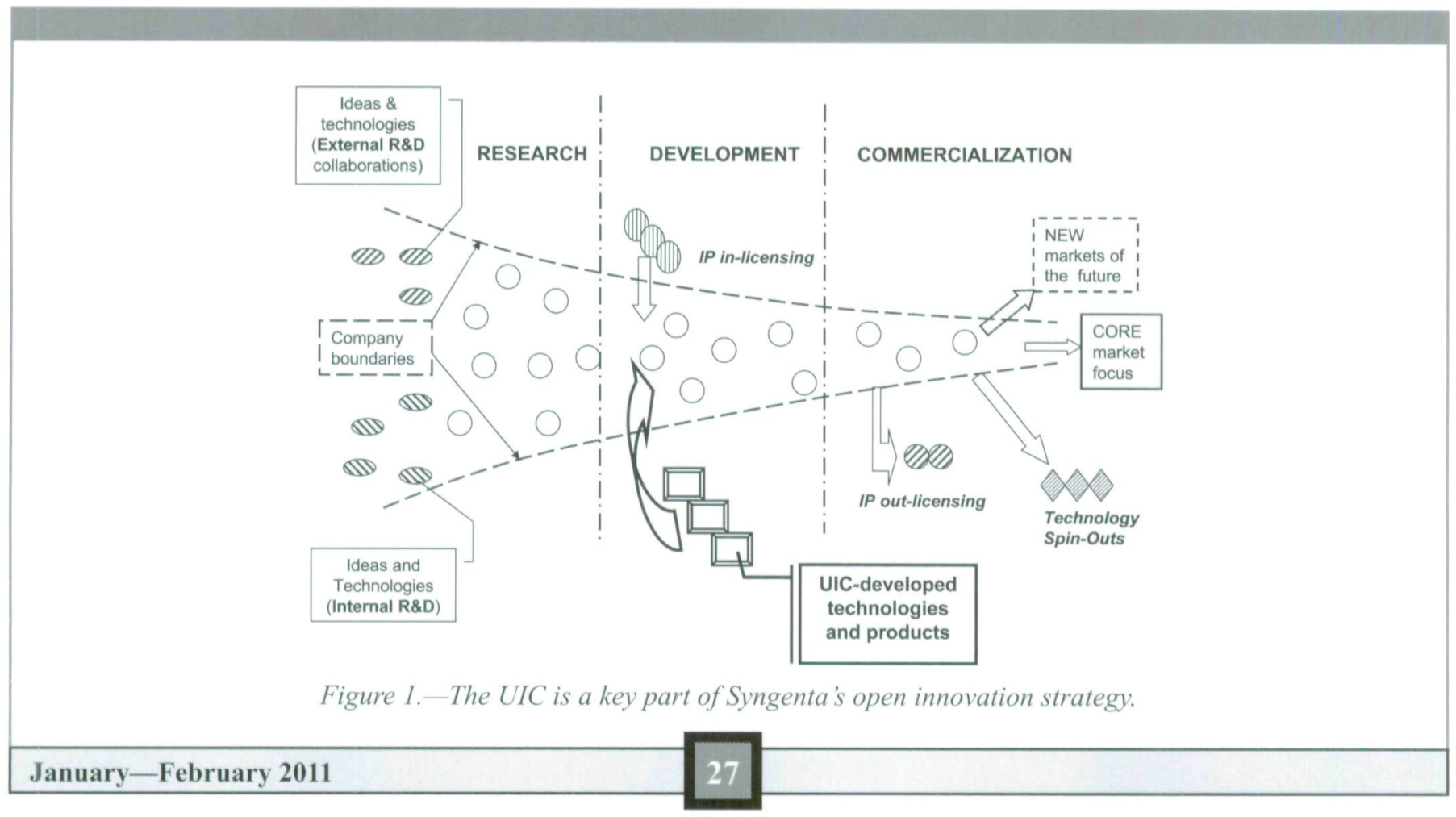




\section{Syngenta's UIC Strategy: A Case Study}

The first Syngenta UIC, the Syngenta Sensors Centre (SSC), opened at the University of Manchester in November 2007. Located in the School of Electrical and Electronic Engineering, so as to access the appropriate design and systems integration competencies, the center is focused on agri-electronics. ${ }^{1}$ The center is charged with researching sensing systems and information communications technologies (ICTs) for agriculture and farming, with a central focus on sensors and knowledgebased approaches to support agriculture. Within this remit, the UIC is working in several specific areas, including new sensing technologies, radio-frequency identification (RFID), wireless sensor networks, energy harvesting, and information and knowledge management.

\section{Developing the Model}

The research program that eventually led to the founding of the UIC emerged from Syngenta's mission to be the leading technology supplier at the front end of the sustainable agriculture supply chain. This impetus, which emerged in the wake of the company's founding in 2000 as a merger of Novartis and AstraZeneca, led Syngenta to develop a strategy for the exploitation of agri-electronics to offer differentiated products and methods to its external and internal customer bases. The specific opportunities for Syngenta within this area had been identified through a series of structured interviews and "landscaping" workshops. These endeavors, which involved business professionals, technologists, and scientists from both within and outside of the company, resulted in the identification of a portfolio of broad, interconnected technology platforms alongside the potential business models that each could service.

Realizing that they did not have sufficient internal resources to fully exploit the proposed portfolio, Syngenta established an external partnerships team charged with carrying out a review of the range of strategies adopted by other multinational companies engaged in re-engineering their product portfolios. This process involved a combination of meetings with peer-group companies from non-agriscience sectors and a review of the academic literature in partnership with the Manchester Business School.

The UIC model that was ultimately adopted provides critical flexibility for the company. The uncertainty inherent to such a disruptive innovation forces an equal degree of commercial and technical innovation; the technical achievement must be matched by an appropriate business model, if it is to produce corporate growth.

\footnotetext{
${ }^{1}$ Information regarding the Syngenta Sensors University Innovation Centre is available at http://www.eee.manchester.ac.uk/research/ groups/sisp/research/syngenta/.
}

The UIC model Syngenta has implemented recognizes this reality. Once a technology is identified, and before significant technical work is done, the UIC works alongside the company's business development teams to identify markets that can be opened up by a new enabling technology. Only when the market and business model are fully developed do UIC researchers work to deliver first-generation prototypes, using direct company funding, to verify the commercial and scientific viability of the concept.

\section{An Exemplar Case Study: From Concept to Commercialization}

During the initial exploration process, the capacity to sense for the presence of a pest or disease within a crop was highlighted as a significant business opportunity. The goal was identified as the creation of an integrated product offering, alongside Syngenta's core crop protection products, to deliver a timely curative treatment to affected crops along with preventative treatment to neighboring crops at increased risk. This would not replace the agronomist, but would elevate the agronomist's decision processes by providing tools to detect crop damage earlier than is possible with current technologies. Some very rudimentary concepts for the required technology were scoped out between Syngenta scientists and the engineers in the Manchester UIC. The conclusion of this initial inquiry was that detecting specific fungal spores would offer the most rapid route to market with acceptable technical risk, sensor cost, and opportunities to secure competitive advantage through IP.

At this stage, no further technical work was undertaken. Instead, the business and product concepts were tested with a future customer base; the United Kingdom was selected as the test region, due to its highly sophisticated agronomic practice, which would facilitate initial uptake of the new approach, and its proximity to the UIC, which reduced logistical difficulties. Syngenta commissioned an investigation to prioritize the most-important crop and fungal disease combinations in the region of interest versus the most-appropriate Syngenta crop-protection products that could be integrated with the new sensor technology. At the same time, the company analyzed what business models could be used to realize this disruptive sensor technology within the overall Syngenta product offering.

In the next stage, the concept was taken to the farming community to test the integrated sensor and crop-protection strategy and ascertain the most suitable route to early adoption. This was achieved by interviewing representatives from a cross section of large commercial farming companies from across the United Kingdom about the business concepts proposed. Interestingly, this process found that the most economically significant diseases did not necessarily translate into the greatest opportunity 
for the new product offering, because growers had already developed work-around methods to manage those disease-crop combinations. With this knowledge, Syngenta and the Manchester UIC team worked with the farming community to evolve an early-adoption strategy. By identifying the most appropriate and commercially significant disease-crop combination where no existing work-around was viable, the team mapped a route for the technology to become established in the market, deliver early financial returns, and then disrupt generic crop-protection practices.

Once this pairing of disease and affected crop was identified, the sensor technology was revisited and the specific business returns for the related products progressed in much greater detail. This iterative business-and-technology-concept development has resulted in new IP being generated to support this first product offering while enabling a downstream IP strategy to be launched for broader markets, within the agri-food sector and beyond.

As this is a disruptive approach, there is, by definition, no current provider of the overall service. Instead, there are individual component suppliers and potential end users, most notably farmers. As a consequence, a systems integration provider will have to be incubated out of the SSC or one of the technology supply-chain partners. This is likely to occur between the development and commercialization phases. The transitioning of key assets and personnel from the SSC may then become a potential cause of conflict between the University and Syngenta, as resources and capability are shifted from the UIC. This situation will be managed by moving those dedicated assets and personnel associated with a particular commercial activity wholly into the new business. Resources that need to be shared between the SSC and the new entity will then be divided and funded, on a prorata basis, through a precommercialization agreement between the university and Syngenta.

\section{Evolution of the Model}

A key mission of the UIC is to deliver long-term, mediumterm, and some short-term technologies to meet perceived market needs. However, this is not the full story; revenue returns must be generated from these innovative products and techniques. In many cases, the impact will be wider than the parent business, as there will be costs associated with introducing enabling technologies that may spread resources across intermediary businesses, such as farmers, distributors, retailers, or crop processors. Each of the affected parties will need to see gains from the new technologies, or adoption will be slow or nonexistent.

The UICs are currently not configured to meet this challenge, and experience has shown that the business analysts within the company are often too specialized in specific product lines to provide the required level of entrepreneurial thinking and resource allocation expertise.

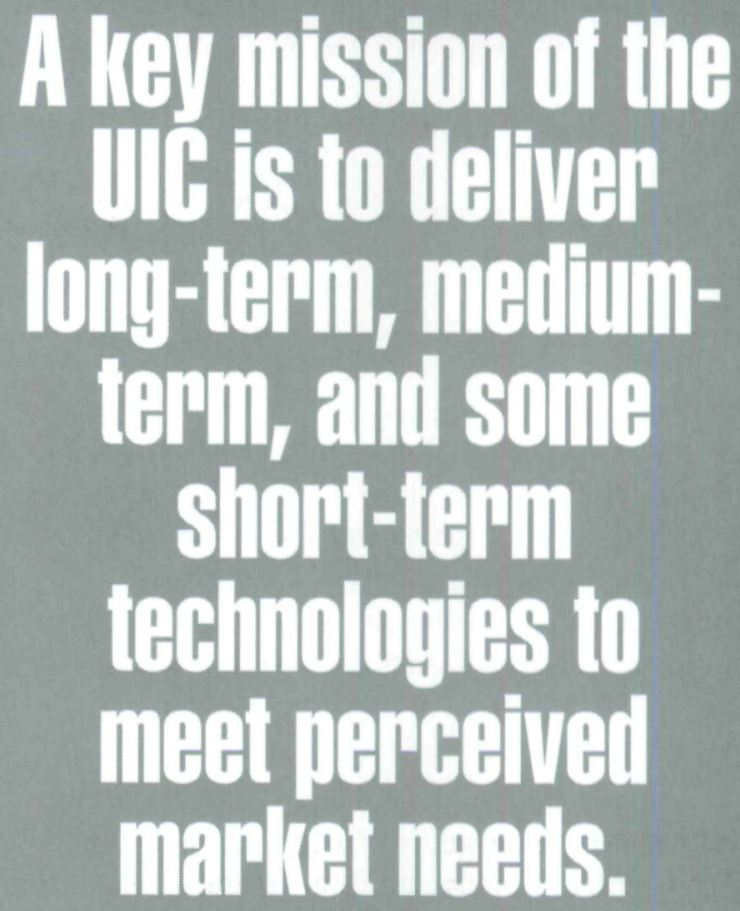

The Syngenta external partnership team and the SSC are now working with business academics and external nonspecialist consultants to bridge this vital gap. These groups are tasked with defining the magnitude of the immediate and longer-term markets and exploring how stakeholder businesses can be restructured to allow them to benefit from the agri-electronic technology.

\section{Lessons Learned}

Syngenta's UIC model has been structured to deliver efficient ways of transforming research into potentially profitable products or techniques in new areas of business. Placing the research work outside of the company has made available scientific strengths that Syngenta did not previously have; not having access to the UIC would have prevented the company from identifying and progressing project ideas (Grieve et al. 2009). At the same time, the parallel development of new business models allows even radical technological models to be assessed in a commercial context and benefit from the feedback that such analyses can provide. The resulting body of knowledge should be easier to reabsorb into the mainstream activities of the firm.

However, this absorption remains a challenge. Firms collaborating with universities in arrangements such as UICs must develop some form of translation competence to turn research outputs into commercially exploitable knowledge assets, and the open-innovation paradigm needs to acknowledge the need for this kind of translation competence. This requires a broader view of the open innovation model that underpins innovation, stressing not just the ability to absorb knowledge but also the 
ability to combine and reconfigure knowledge in novel ways (Perkmann and Walsh 2007). As firms look to differentiate themselves from competitors by improving their speed to market, Sherwood and Covin (2008) suggest that a key advantage of this type of collaboration is that it facilitates multipoint, real-time contact between the technology experts of the partner organizations. The translation competency developed as a result of this contact should enable the knowledge-seeking party to rapidly access desired information through the most knowledgeable individuals on an as-needed basis.

The UIC partnership offers benefits and limitations for both the corporate and the university partner (Table 1). The major benefits of the UIC for the corporate partner are that the UIC can help to develop technology and business model combinations that do not currently exist, enabling the company to target new markets with new business models. The partnership also enables company scientists to establish long-term relationships with university academics, and those connections can bring unexpected payoffs down the line. Similarly, academic scientists can benefit from the long-term collaboration that characterizes a UIC by gaining a better appreciation of the business environment complexities that the corporate partner is immersed in. For some universities, this type of strategic alliance is crucial in helping the university to build and maintain a world-class reputation. One of the main challenges in this strategic partnership, especially for university partners, revolves around IP; confidentiality restrictions in the collaboration agreement may restrict the publication of some research undertaken at the UIC. Given the importance of publications to both universities and individual academic scientists, both partners need to explore ways to overcome this barrier.
The parallel development of new husininess models allows given ratilieal technological modds to he assessed in a commercial contert and henefit from the feediliakck that such antalyses ceil provitile.

One option could be to delay publication of some moresensitive research results, but allow publishing some preliminary findings earlier.

Table 1.-The UIC structure provides benefits and limitations for both the company sponsor and the hosting university.

\begin{tabular}{|c|c|c|}
\hline & Benefits & Limitations \\
\hline University & $\begin{array}{l}\text { - Strategic alliance can help university to build a world-class } \\
\text { reputation. } \\
\text { - Presence of UIC/corporate collaboration can help university } \\
\text { attract additional funding. }\end{array}$ & $\begin{array}{l}\text { - The IP restrictions of the collaboration } \\
\text { agreement may create some short-term } \\
\text { restriction on academic publications in the } \\
\text { core theme of the UIC research. }\end{array}$ \\
\hline & $\begin{array}{l}\text { - Some UIC-developed technologies may be licensable in } \\
\text { areas outside UIC focus via university spin-outs. } \\
\text { - Academics may benefit from insights into business strategies } \\
\text { of partnering company. }\end{array}$ & $\begin{array}{l}\text { - Some academics may feel they are locked in } \\
\text { to meeting specific needs of one industry } \\
\text { partner, leaving little opportunity to explore } \\
\text { research collaborations with other firms. }\end{array}$ \\
\hline Company & $\begin{array}{l}\text { - Company scientists can collaborate in blue-sky research and } \\
\text { establish long-term relationships with academic researchers. } \\
\text { - Company gains access to wider expertise in the university. } \\
\text { - The UIC may help the company to develop technological } \\
\text { combinations that do not currently exist. } \\
\text { - UIC outputs can help company to target new markets in } \\
\text { the future. }\end{array}$ & $\begin{array}{l}\text { - The company may lack the internal } \\
\text { entrepreneurial capability to effectively } \\
\text { exploit UIC outputs in new markets. } \\
\text { - For a company managing many partnerships, } \\
\text { there is a danger of becoming too detached } \\
\text { from the partnership compared to other } \\
\text { external collaborations. }\end{array}$ \\
\hline
\end{tabular}


Ultimately, the critical measure of success for a UICbased strategic partnership, from the business's point of view, is that the UIC delivers technologies and enables business models that make a significant commercial difference. Realizing this goal may require a significant gestation period. The SSC was established with a threeyear funding life. That has since been extended to five years, but real returns are not likely to be seen until years seven or eight. This long lead time requires a long-term investment from the host company, which may be difficult to guarantee, especially if there are personnel changes in senior management.

Syngenta, like many other science and technology-based companies, maintains a range of external partnerships. This diversity of activity raises the danger that the company might be distracted and thus become too detached from its UICs; this would lead to a failure to maximize the potential benefits of the collaboration. To avoid this, Syngenta stresses the importance of initiating informal linkages with all UICs, especially those that are located furthest from corporate headquarters (in China and Australia). These informal linkages keep individuals within the company aware of the UIC and its activities, maintaining corporate involvement at the individual level. One mechanism for fostering these linkages is a conference that brings together corporate and UIC scientists to discuss developments and share findings. The company already holds an annual conference in agricultural sciences in China to enable Syngenta research staff and sponsored $\mathrm{PhD}$ researchers to come together with other invitees from Chinese universities and government ministries. Replicated in other regions, this practice could help promote more informal, face-to-face linkages between the UICs and Syngenta internal staff.

\section{Conclusion}

For Syngenta, establishing a long-term relationship with a university has provided enormous benefits, even beyond the technology. Syngenta scientists now have the opportunity to co-supervise $\mathrm{PhD}$-candidate researchers working within the UIC, creating enduring connections between the industry and academia and encouraging researchers to work on projects that not only address an academic issue, but are also of interest to industry. These collaborations provide company scientists the opportunity to produce joint scientific publications with university research staff and build the informal linkages that sustain the UIC.

Our insights with regard to the SSC may be useful to large firms and universities interested in exploring this type of strategic partnership. As a key part of an open innovation model, the UIC concept can help develop technology platforms for new and existing markets and create a long-term pipeline for business and technology innovation. In the future, it will be interesting to observe whether other science and technology-based companies facing challenges to established core business will follow a similar path to form strategic alliances with research-intensive universities in something resembling the UIC model. Those that do can find a challenging and productive model to consider.

We would like to thank Dr. Mike Bushell, Head of External Partnerships at Syngenta Jealott's International Research Centre (Bracknell, UK), for his helpful insights.

\section{References}

Arundel, A., and Geuna, A. 2004. Proximity and the use of public science by innovative European firms. Economics of Innovation and New Technology 13(6): 559-580.

Broström, A., McKelvey, M., and Sandström, C. 2009. Elite European universities and the R\&D subsidiaries of multinational enterprises. In Learning to Compete in European Universities, ed. M. McKelvey and M. Holmen, 251-277. Cheltenham, U.K.: Edward Elgar.

Chesbrough, H. 2003. Open Innovation: The New Imperative for Creating and Profiting from Technology. Boston: Harvard Business Press.

Coombs, R., and Georghiou, L. 2002. A new industrial ecology. Science 296 (19 April): 471

Cui, Z., Loch, C. H., Grossmann, B., and He, R. 2009. Outsourcing innovation. Research-Technology Management 52(6): 54-63.

European Commission. 2008. Challenging Europe's Research: Rationales for the European Research Area (ERA). Report of the ERA Expert Group, EUR 23326, DOI 10.2777/39044. Luxembourg: Office for Official Publications of the European Communities.

Grieve, B., Bushell, M., Lant, M., Georghiou, L., and Malik, K. 2009. Changing the rules of the game for future agriculture: The university innovation centre model. In PICMET 2009 Conference Proceedings, 288-298. Portland, OR: IEEE.

Howells, J., Nedeva, M., and Georghiou, L. 1998. Industry-Academic Links in the UK. Final Report to Higher Education Funding Council for England (HEFCE), the Higher Education Funding Council for Wales and the Scottish Higher Education Funding Council, HEFCE Ref 98/70. Bristol: HEFCE.

Malik, K. 2004. Coordination of technological knowledge flows in firms. Journal of Knowledge Management 8(2): 64-72.

Nelson, R. R. 2001. Observations on the post-Bayh-Dole rise of patenting at American universities. The Journal of Technology Transfer 26(1-2): 13-19.

Perkmann, M., and Walsh, K. 2007. University-industry relationships and open innovation: Towards a research agenda. International Journal of Management Reviews 9(4): 259-280.

Roessner, D., Ailes, C., Feller, I., and Parker, L. 1998. Impact on industry of participation in NSF's engineering research centers. Research-Technology Management 41(5): 40-44.

Rudy, A. P., Coppin, D., Konefal, J., Shaw, B. T., Eyck, T. T., Harris, C., and Busch, L. 2007. Universities in the Age of Corporate Science: The UC Berkeley-Novartis Controversy. Philadelphia: Temple University Press.

Shane, S.A. 2005. Economic Development through Entrepreneurship: Government, University and Business Linkages. Cheltenham, U.K.: Edward Elgar.

Sherwood, A. L., and Covin, J. G. 2008. Knowledge acquisition in university-industry alliances: An empirical investigation from a learning theory perspective. Journal of Product Innovation Management 25(2): 162-179. 
Copyright of Research Technology Management is the property of Industrial Research Institute, Inc. and its content may not be copied or emailed to multiple sites or posted to a listserv without the copyright holder's express written permission. However, users may print, download, or email articles for individual use. 